\title{
The Application of Polyurethane Composite Material in the Field of Building Exterior Wall
}

\author{
Zhiwen ZHAO \\ Hangzhou Polytechnic \\ Hangzhou ,Zhejiang 311402, China
}

\begin{abstract}
The research analyzed the application status of $\mathbf{P u}$ aluminum composite panels, summarizes research status of thermal insulation material in the domestic and foreign, especially the related properties of materials, such as combustion, heat insulation, weather resistance; related development and external wall insulation decorative integration materials present has done some introduction. The paper use aluminum alloy decorative board with thermal insulation and integrated decoration produced by the factory, combined with a keel and anchor bolt connection, is directly fixed on the outer wall of a building, can realize the building exterior wall thermal insulation decorative function, the system also has a good waterproof, fireproof performance, construction process comprehensively can use dry homework.
\end{abstract}

Keywords: heat preservation; decoration; fireproof; waterproof; dry construction; Pu aluminum composite panels;

\section{INTRODUCTION}

With the rapid development of the productive forces, global industrial information technology continues to accelerate, the consumption of energy and resources is more and more high, nearly $30 \%$ of them are generated by the energy consumption of the building, coupled with the building materials production process of consumption, building energy consumption in society's total energy consumption accounted for 4607047070, while China's urban construction is in the rush hour. Building energy conservation has become one of the important fields of China's energy-saving emission reduction. In the high-speed development of our country economy at present, can reduce the energy consumption of buildings by the following four kinds of effective ways to do the construction of energysaving work [1]: one is to enhance and improve the building thermal insulation properties; two is that the efficiency of the system can be used to improve the heating, air conditioning, lighting and so on; three is the rational use of new and renewable sources of energy; four is to strengthen the operation and management of equipment system with. And among them, to strengthen the building of thermal insulation to reduce energy consumption of building, this method is most effective.

The thermal insulation decoration system of aluminum alloy polyurethane composite decorative board for exterior wall, which introduce German technology, suitable for
China's national conditions of thermal insulation and decoration integrated technique to form to digest and improvement, system overcomes the existing insulation system cracking, leakage, shedding and construction quality should not be control and so on, is a kind of wall technology advanced, safe and reliable thermal insulation decorative application technology.

\section{STUDY ON THE COMBUSTION PROPERTIES OF PU ALUMINUM COMPOSITE PANELS}

\section{A. Experimental equipment}

The cone calorimeter is a kind of advanced instruments and equipment of material combustion and ignition characteristics, can collect the materials in the combustion heat release rate, the combustion product ingredients, smoke parameter, weight loss rate, material ignition time, specific extinction area, effective heat of combustion parameters. Measured by its data accuracy is high and intuitive, able to describe the problem of science.

\section{B. Experimental materials}

Exterior insulation integrated board have many varieties, because $\mathrm{Pu}$ aluminum composite panels this material is widely used in the market, but also have good decorative effect, simple construction and higher quality advantages, this paper chooses this as a typical exterior wall insulation decorative integration material is studied, and the structure of $\mathrm{Pu}$ aluminum composite panels is relatively simple and suitable for basic sample.

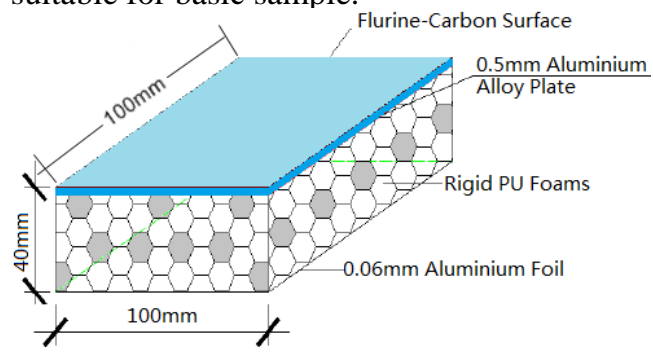

Fig.1 The sample physical structure of PU-aluminum alloy composite plate

This experiment of the specimen material is polyurethane - aluminum alloy composite plate. Its surface thickness is $0.5 \mathrm{~mm}$ aluminum plate, aluminum plate surface is oxygen fluorine carbon paint layer, and has good decorative effect, good weathering performance, acid and alkali resistant performance is high, self-cleaning etc.; the middle layer is a 
polyurethane hard foam thickness is $40 \mathrm{~mm}$, coefficient of heat conductivity is less than or equal to $0.024 \mathrm{~W} / \mathrm{m}-\mathrm{K}$, low thermal conductivity, excellent thermal insulation performance; the inner layer is an aluminum film with the thickness of $0.06 \mathrm{~mm}$, and its role is to prevent the spread of polyurethane foam insulation materials, prevent aging, to ensure that the effect of heat insulation materials. The thermal resistance: $2.09 \mathrm{~m} 2-\mathrm{k} / \mathrm{W}$ (in which: plate heat resistance is $1.69 \mathrm{M} 2-\mathrm{k} / \mathrm{W}$, the thermal resistance of air layer is $0.4 \mathrm{M} 2 \mathrm{k} / \mathrm{W})$, the heat transfer coefficient $\mathrm{K}=$ $0.48 \mathrm{~W} / \mathrm{m} 2$ - K. (see Figure 1).

In accordance with the cone calorimeter experiments were conducted on the specimens standard requirements, the $\mathrm{Pu}$ aluminum composite panels cut into the heating surface area of block $100 \mathrm{~mm} \times 100 \mathrm{~mm}$, because the surface of the material is aluminum plate, the flatness of the composite requirements, material thickness is $40 \mathrm{~mm}$.

\section{Experimental results and its analysis}

(1) The ignition time analysis

Through the record of the six groups experiment at different radiation conditions, the test block ignition time mean were: $116 \mathrm{~s}, 68 \mathrm{~s}, 52 \mathrm{~s}, 38 \mathrm{~S}, 30 \mathrm{~s}, 28 \mathrm{~s}$, thermal radiation intensity of the corresponding is as shown in Table 1, we can see that the ignition time is longer at $25 \mathrm{~kW} / \mathrm{m} 2$, ignition time with the heat flux increased with decreasing the decrease rate. The variation tendency of ignition time and radiation flux is consistent with results of wood by Zhou Yupeng et al ${ }^{[4]}$.

Table 1. The relation table between radiation flux and ignition time

\begin{tabular}{l|r|r|r|r|r|r}
\hline $\begin{array}{l}\text { Radiant flux } \\
\left(\mathrm{KW} / \mathrm{m}^{2}\right)\end{array}$ & 25 & 30 & 35 & 40 & 45 & 50 \\
\hline $\begin{array}{l}\text { Ignition time } \\
(\mathrm{s})\end{array}$ & 116 & 68 & 52 & 38 & 30 & 28 \\
\hline
\end{tabular}

(2) The heat release rate

Heat release rate is an important parameter of the dangerous degree of fire. Figure 2 is the heat release rate of $\mathrm{Pu}$ aluminum composite panels block under the different radiative heat flux, it can be seen very similar curve of oscillation trend from the figure block in six different radiation conditions. After the fire, the combustion heat release rate of intense, nearly straight line rise rapidly, reaching the peak; subsequently decline, speed ratio rises relatively slowly, then there is a less obvious convex, $25 \mathrm{~kW} / \mathrm{m} 2$ showed more obvious. With the slow combustion, heat release rate falls to trough, then a gentle oscillation process, heat release rate values are almost not change. So we can draw the conclusion that the heat release law of material under different radiation intensity is similar, the radiation intensity is higher, the combustion is more intense, ignition time faster, reaching peak combustion time is shorter, and the total heat release is also more.

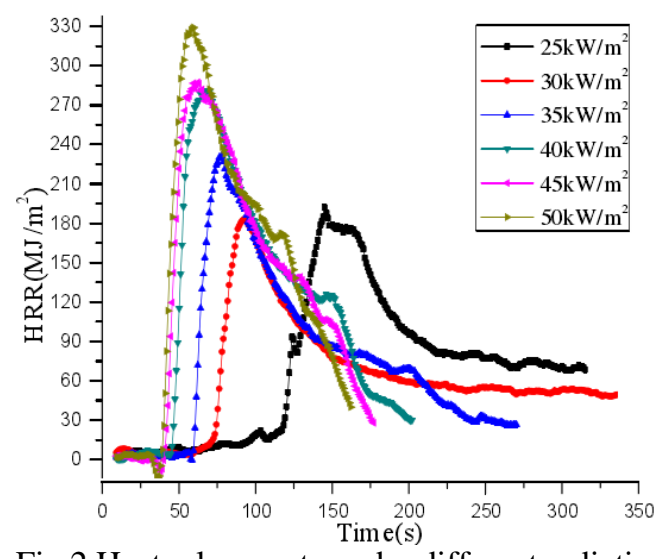

Fig. 2 Heat release rate under different radiative heat flux

(3) Concentration of smoke composition

At the time of the fire, the combustion releases large amounts of gas, such as $\mathrm{CO} 2, \mathrm{CO}, \mathrm{HCN}$ etc.. Most of these gases are toxic and harmful gases, can make a person asphyxial poisoning, is the key factor of casualties. When the $\mathrm{CO}$ concentration in the air over 100ppm, CO2 over 2000ppm will cause harm to the human body, has an important significance in gas study on the characteristics of polyurethane - aluminum alloy composite plate burning production. Figure 3 4 are the volume fraction of $\mathrm{CO}, \mathrm{CO} 2$ change over time curve. The change trend of the volume fraction of products $\mathrm{CO}$ and $\mathrm{CO} 2$ is according with the change of time and the heat release rate agreement.

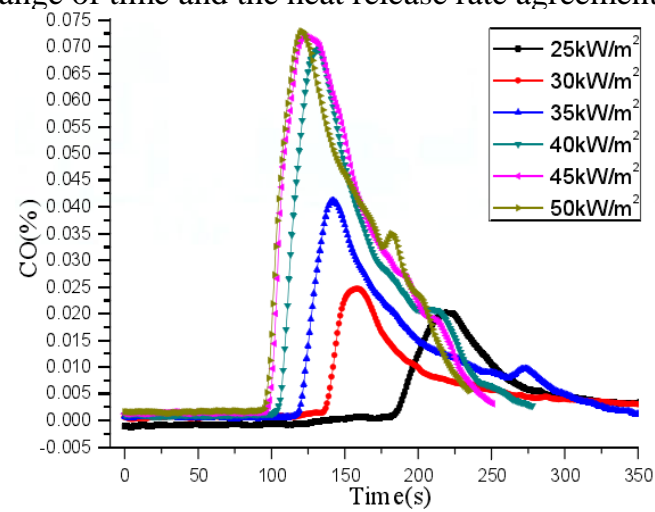

Fig.3 The change curve of $\mathrm{CO}$ volume percentage with time

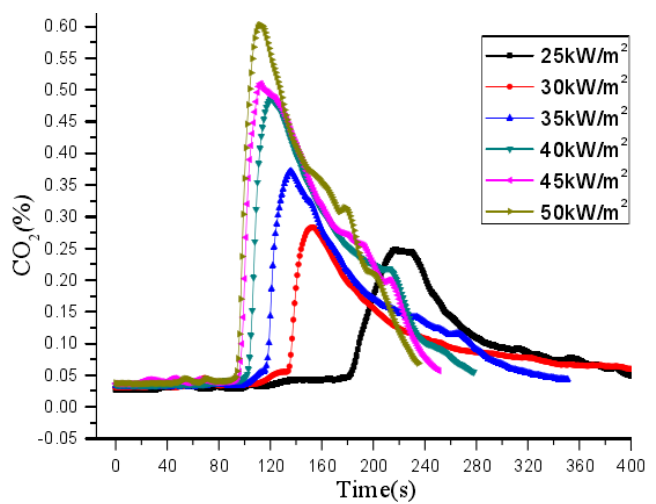

Fig.4 The change curve of $\mathrm{CO} 2$ volume percentage with time 
(4) Study on insulation performance

According to China's climate zones and around the requirements of the living environment, the paper establish the suitability performance of Building model for material thermal insulation and the applicability of the material based on the Ecotect software, each model volume is $6000 \mathrm{~mm} *$ $4000 \mathrm{~mm} * 3000 \mathrm{~mm}$ plane that is as shown figure 5. Model building envelop materials properties is as shown in table 2.

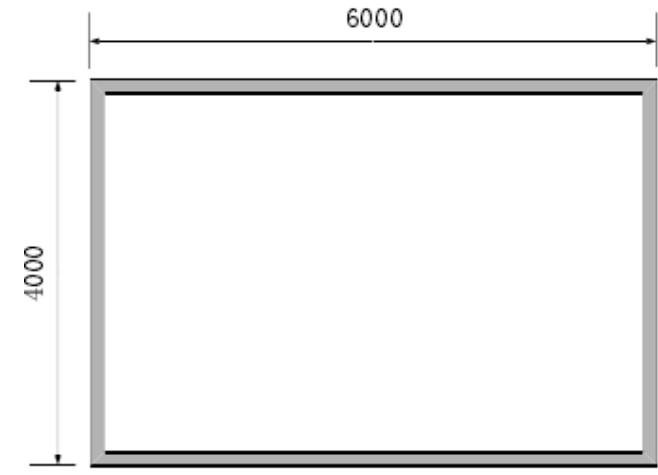

Fig.5 Planar graph model (unit: $\mathrm{mm}$ )

Table. 2 the materials properties of model building envelop

\begin{tabular}{c|l|r|r|r|r}
\hline \multicolumn{2}{c|}{ Material name } & $\begin{array}{l}\text { Thickness } \\
(\mathrm{mm})\end{array}$ & $\begin{array}{l}\text { Density } \\
\left(\mathrm{Kg} / \mathrm{m}^{3}\right)\end{array}$ & $\begin{array}{l}\text { Specific heat } \\
(\mathrm{J} / \mathrm{Kg} . \mathrm{K})\end{array}$ & $\begin{array}{l}\text { Thermal } \\
\text { conductivity } \\
(\mathrm{W} / \mathrm{m} . \mathrm{K})\end{array}$ \\
\hline Basics & Red brick & 240 & 2000 & 836.8 & 0.711 \\
\hline \multirow{2}{*}{ Wall } & Concrete & 240 & 1600 & 656.9 & 0.335 \\
\cline { 2 - 6 } & Plaster & 10 & 1250 & 1008 & 0.431 \\
\hline
\end{tabular}

We can see in the cold from Figure 6, throughout the day indoor temperature fluctuation amplitude is small between heat preservation layer and non-insulation, the heat dissipation is relatively slow, and the outdoor temperature began to decrease after 16 hour, the indoor temperature basically has no too big change, the average temperature than 1 1.5 DEG C without insulation floors. At the same time, we can see the insulation effect of the concrete wall has good effect than brick.

In the hot weather, as shown in Figure 7, without insulation layer A model, all day temperature fluctuations, brick structure performance is particularly evident in the room. In the thermal insulation layer, the indoor temperature change trend model of brick and concrete structures are almost exactly the same. The brick structure, it has high 0.5 1.5 degrees Celsius of a heat preservation layer indoor temperature than non-insulation, concrete structure is high about $0.5 \sim 1$ degrees celsius.

From the graph, we discover not hard, whether it is cold or hot day the most, indoor temperature curve of the thermal insulation layer is same, the insulation effect of the concrete wall is relatively good, but the temperature difference is not big, in the cold temperature of about 0.3 , the hot weather is about 0.2 DEG C.

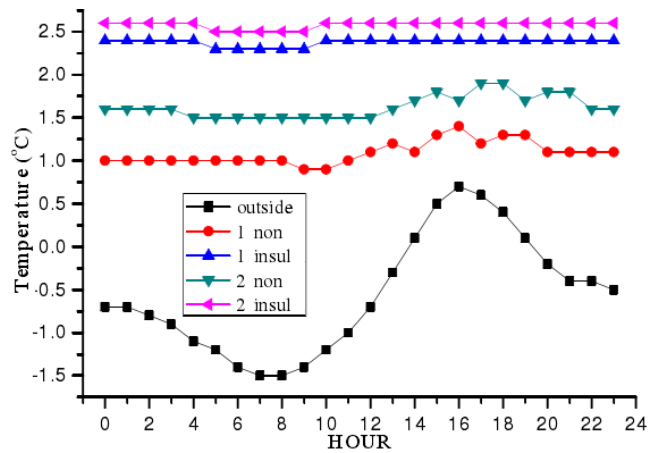

Fig.6 The temperature chart of a area in most cold (1.18) (1: brick; 2: concrete)

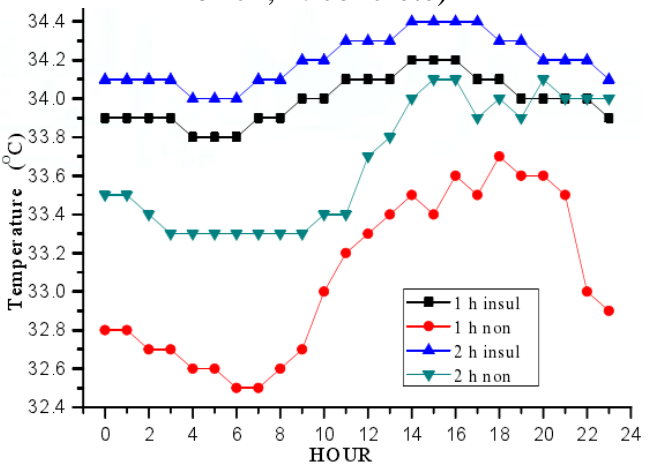

Fig.7 The temperature chart of a area in most host (8.23) (1: brick; 2: concrete)

\section{APPLICATION OF ALUMINUM ALLOY POLYURETHANE COMPOSITE BOARD IN EXTERIOR WALL HEAT INSULATION DECORATION SYSTEM}

Aluminum alloy polyurethane composite decorative board for exterior wall thermal insulation decoration system (hereinafter referred to as the system) is that the aluminum alloy polyurethane composite decorative board is fixed on the keel via bolts or rivets (plate through mortise inserting), keel through the metal anchor bolt or nylon anchor bolt directly anchored in the outer wall of buildings, and then use the spare parts and material of door and window openings the cornice, parapet, and other parts of thermal insulation and decoration processing, finally has formed a good thermal insulation performance, exterior wall but also have good decorative effect of the thermal insulation decorative integration, the decoration effect is to rely on the Luo Bao board surface fluorocarbon coating color and pattern reflected, insulation performance is jointly realized by Luo Baoban and air layer formed relatively static Lo Po between the plate and the wall (see Fig. 8-9). 


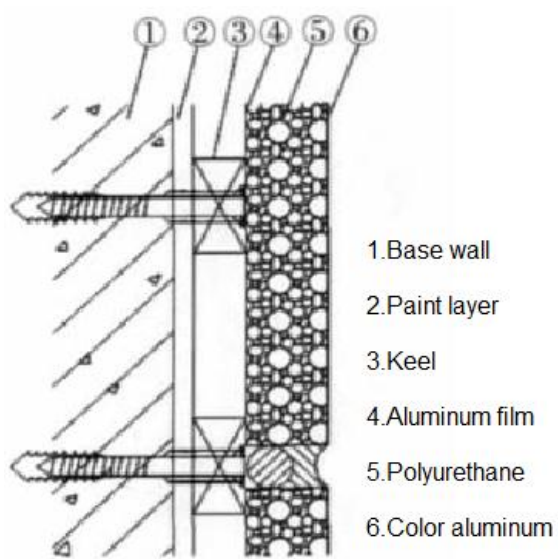

Fig. 8 The basic structure of the system on new building

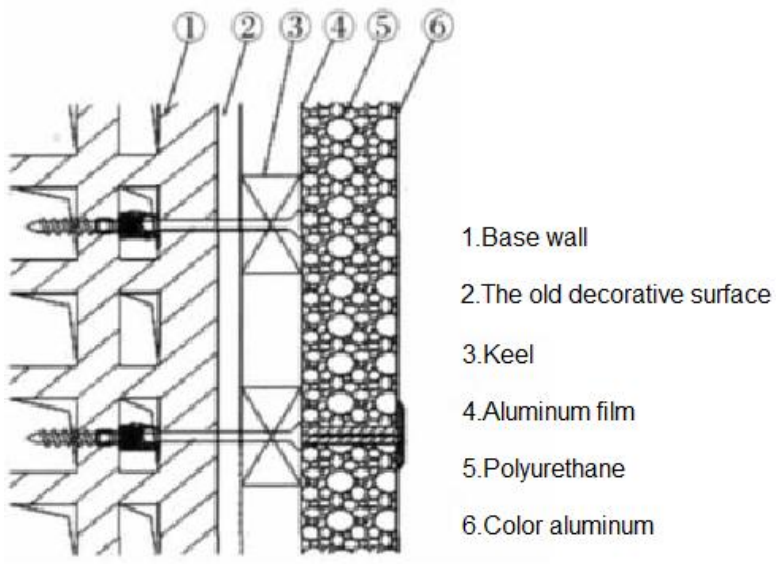

Fig.9 The basic structure of the system on old building

\section{CONCLUSIONS}

Aluminum alloy polyurethane composite decorative board of exterior wall thermal insulation decoration system, used factory production, dry installation, high ratio of performance to price, well meet the requirement of building energy saving, decoration, fire prevention, waterproof and other aspects of the technology, at the same time, the system engineering assurance construction quality and reliability. Therefore, utilization of system will improve our quality of buildings, reduce energy consumption of the building, has an important significance in the development of building energy saving in china.

\section{REFERENCE}

[1] Song Changyou, Chen Danlin, Huang Zhenli, Ji Guang. Study on the system of high-rise building external wall thermal insulation technology of refractory [J]. The construction of science. .2008, 24, (2): $93-104$

[2] $\mathrm{Li}$ Xiangzhou. The status and trend of exterior wall insulation technology [J]. The construction application. 2005 (10): 54-56.

[3] Song Changyou, Ji Guangqi, Chen Danlin, Zhu Chunling. Analysis of fire safety of external thermal insulation system [J]. Building Science. 2008,24 (2): 8-12

[4] Song Changyou, Huang Zhenli, Ji Guang, Chen Danlin. Discussion on the current situation of fire protection technology of exterior insulation of external wall and its problems [J]. The construction of science. 2008, 24 (2): 1-7

[5] Meng Cong. Research on the building external wall thermal insulation fireproof safety system [D]. Qingdao Technological University, 2012 